\section{UMCLASSTFIED \\ This teport is tor intemal use. Do nöt give it further distribution or refer to it in any extemal publication.}

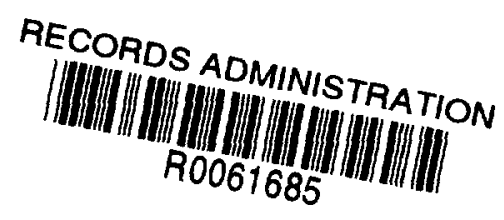

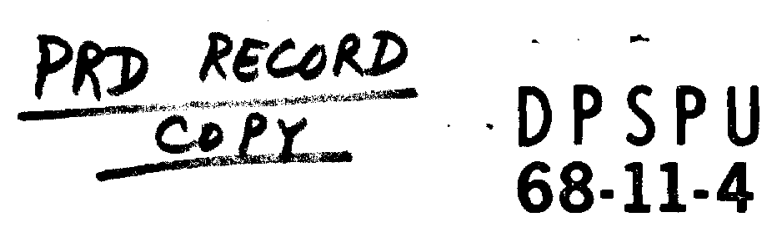

File Code I15
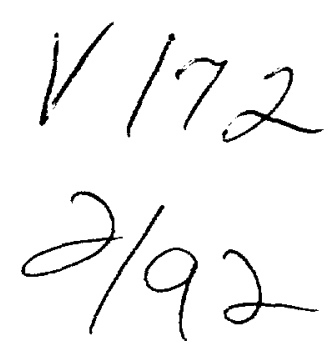

\title{
PORTABLE MONITOR FOR TRITIUM IN AIR
}

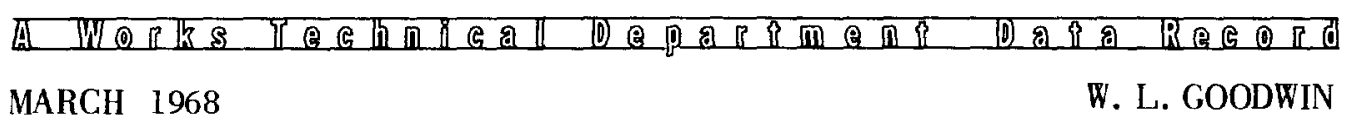




\section{Introduction}

In any process involving tritium, there is the possibility that some of it, in the form of tritium gas or tritiated water vapor, may escape and become airborne (1). A high-range instrument (10 $10^{4}$ RCG) is needed in emergencies to quantitatively measure tritium in air so that personnel can be protected as required from the radiation hazard associated with tritium. Requirements for such an instrument are that it be:

$\diamond$ Portable.

$\diamond$ Reliable.

$\diamond$ Sensitive to $1 \times 10^{-4}$ microcurie of tritium per cubic centimeter of $\operatorname{air}(\mu \mathrm{Ci} / \mathrm{cc})$.

$\diamond$ Insensitive to fire and smoke.

$\diamond$ Insensitive to variations in wind velocity and humidity.

$\diamond$ Easy to use and read.

Period covered: January 1 to November 13, 1967.

\section{Summary}

A portable monitor has been developed which accurately measures tritium concentrations between $1 \times 10^{-4}$ and $1 \times 10^{-1} \mu \mathrm{Ci} / \mathrm{cc}$ of air. The instrument consists of five basic sections: air pump, deionizer, ionization chamber, logarithmic electrometer amplifier, and high voltage power supply. An internal rechargeabde 12-volt battery powers the entire monitor. A connector is provided so that an external 12-volt battery can be used if the monitor is needed for extended periods of time. Total weight of the unit is 22 pounds and the overall dimensions are $10.5 \times 6.8 \times 13.2$ inches (figure 1 ). The instrument has been calibrated by comparison with a Kanne monitoring system and evaluated under varying levels of tritium activity. Readings were reproducible within $\pm 10 \%$ of reading.

\section{Discussion}

The five basic sections of the instrument and its calibration are discussed under the following headings. 


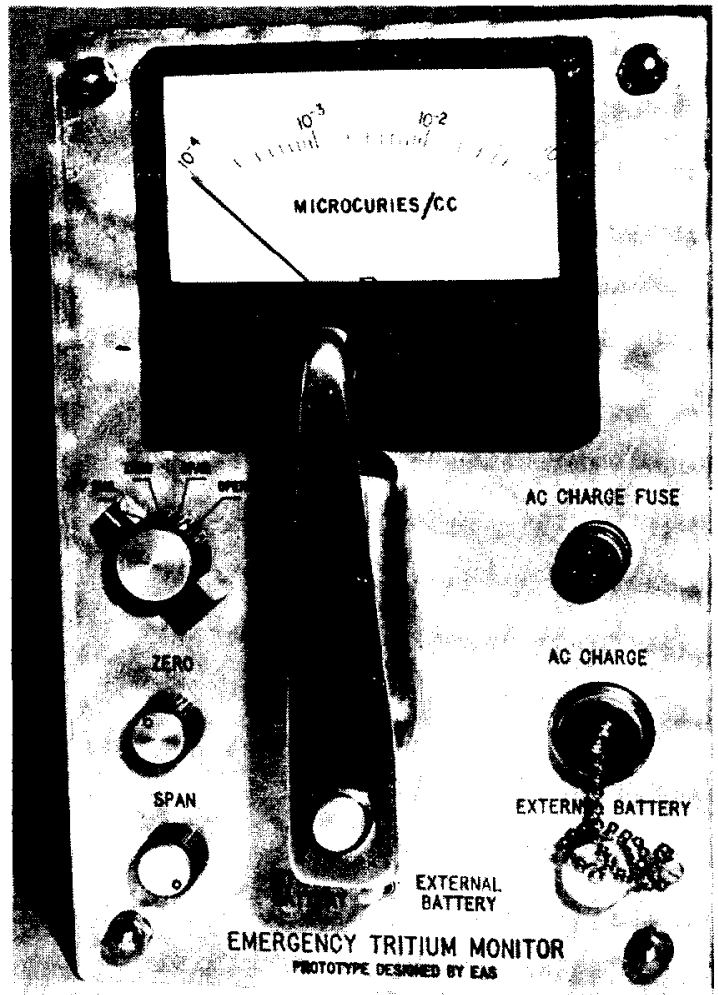

FIGURE 1. PORTABLE TRITIUM MONITOR. Approx 1/3X, DPSPF 12079.4.

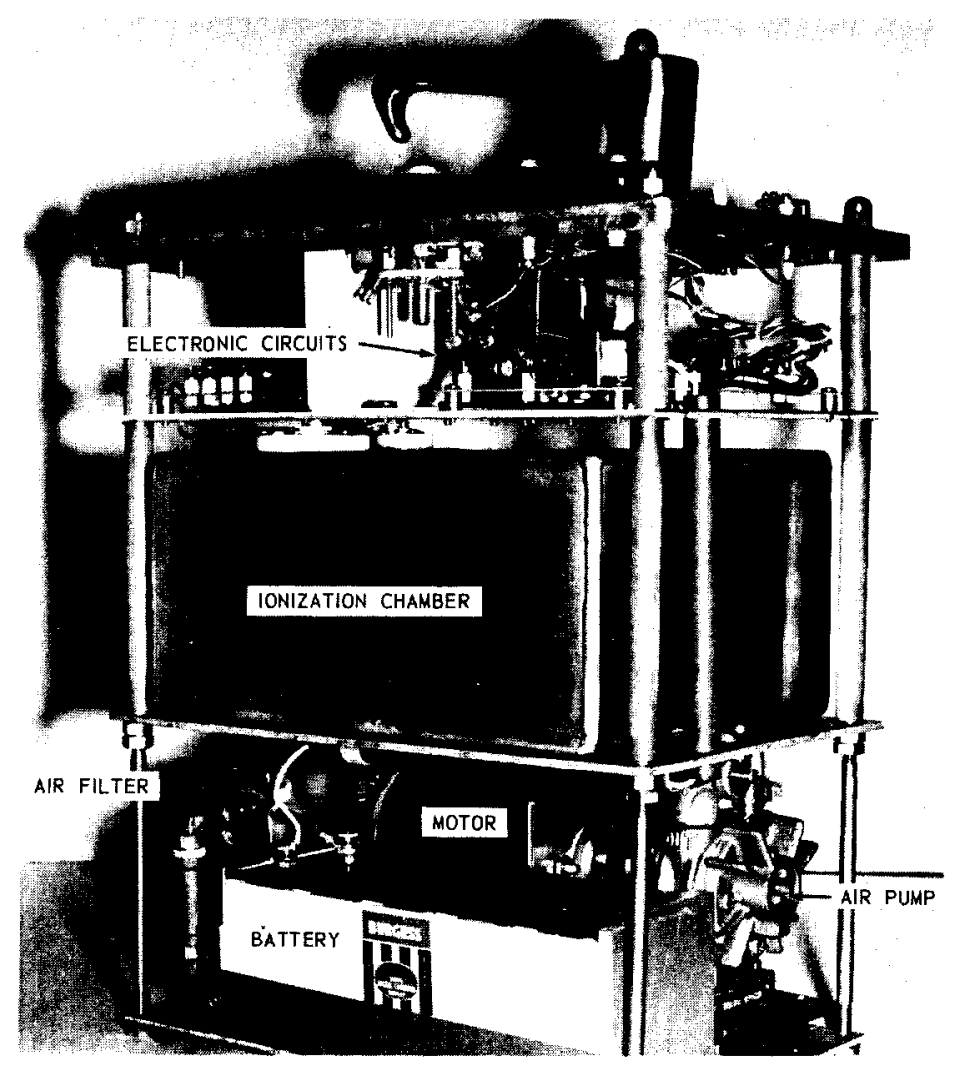

FIGURE 2. TRITIUM MONITOR WITH CASE REMOVED. 


\section{AIR PUMP}

The motor and air pump are housed in the bottom of the instrument (figure 2). The motor is a permanent-magnet type, powered by the rechargeable 12-volt battery. This battery will power the entire monitor for 1.5 hours of continuous operation. The air pump is a positive displacement vacuum pump which produces an air flow of 1 cfm. This type of pump is used so that long lengths of hose can be used for remote monitoring.

\section{DEIONIZER}

Since it is desirable to collect only those ions which are produced by tritium beta radiation within the ionization chamber, a deionizer (figure 3 ) is provided to remove as many ions as possible from the air before it enters the ionization chamber. Free ions may be present in the atmosphere being sampled because of ionization produced by smoke, radiation, etc. The deionizer has a volume of $500 \mathrm{cc}$ and a potential of $1200 \mathrm{~V}$ DC is supplied to its walls by the highvoltage power supply.

Two absolute air filters connected in parallel immediately precede the deionizer, to clean the air being sampled before it passes through the deionizer and ionization chamber.

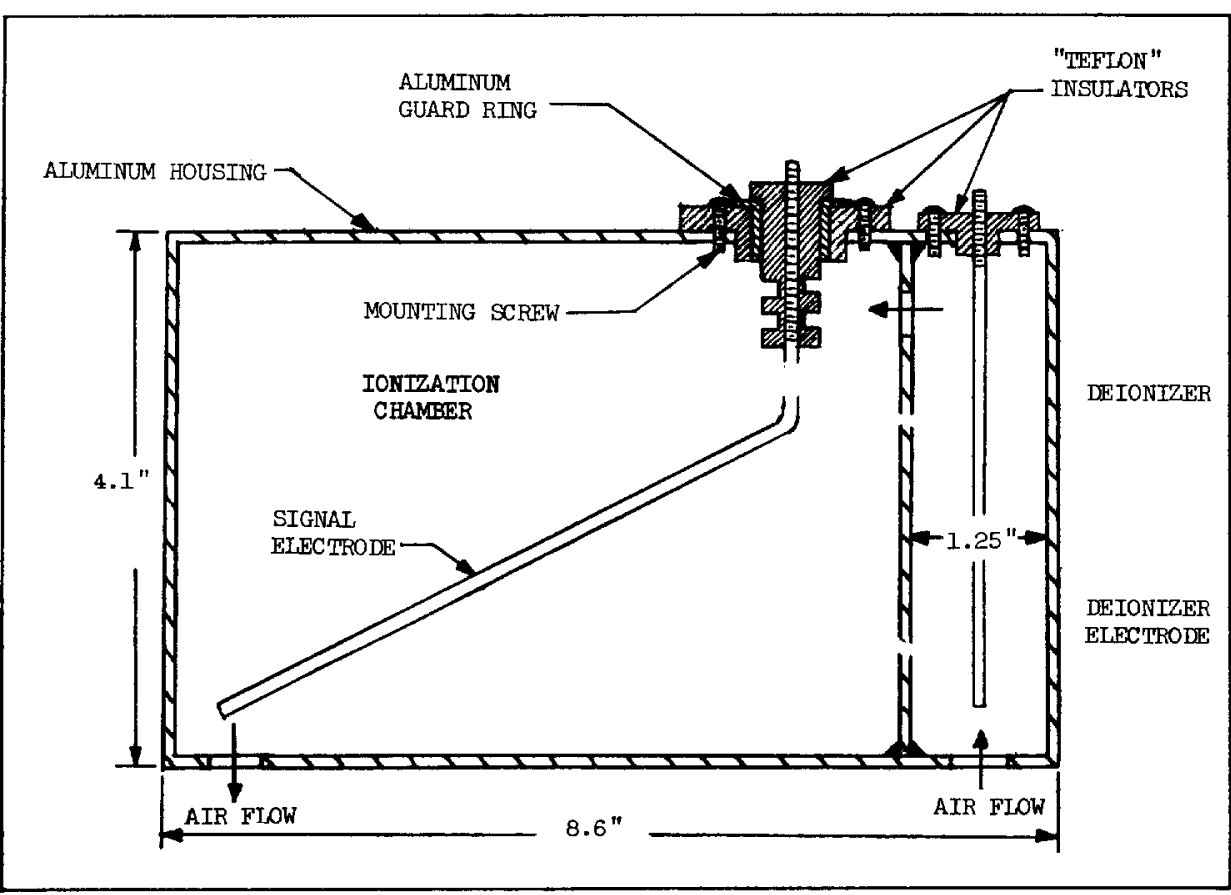

FIGURE 3. CROSS-SECTION OF THE IONIZATION CHAMBER AND DEIONIZER 
IONIZATION CHAMBER $(2,3,4)$

The ionization chamber (figure 3 ) is made of aluminum, and has a volume of $2900 \mathrm{cc}$ and a sensitivity of $3 \times 10^{-9} \mathrm{amp} / \mathrm{\mu Ci} / \mathrm{cc}$. The chamber inner surfaces are highly polished to minimize contamination buildup. A guard ring is provided around the signal electrode to minimize leakage currents caused by high humidity inside the ion chamber.

\section{LOGARITEMIC ELECTROMETER AMPLIFIER $(5,6)$}

The electrometer amplifier (figure 4) employs all solid state components except for the input electrometer tube. This amplifier was chosen because of its stability, accuracy, and high current gain. It is a three stage DC amplifier in which the input tube serves as a logarithmic electrometer. The circuit employs $100 \%$ negative feedback for stability and has a current gain of approximately $1 \times 10^{8}$. The amplifier is accurate within $\pm 3 \%$ of reading over the range used, and has a very low drift rate after one or two minutes warmup. Two thermal time-delay relays are used to reduce transients produced while switching the two calibration resistors in and out of the circuit. The use of these relays allows the response time of the circuit to be short during calibration and operation. A single logarithmic scale is used on the indicating meter to make meter reading fast and simple.

\section{HIGH VOLTAGE POWER SUPPLY (7)}

The high-voltage power supply (figure 4) is a DC to DC converter that develops 1200 volts for the deionizer and ionization chamber by voltage doubling. A (transistorized) blocking-oscillator circuit oscillates at approximately $800 \mathrm{~Hz}$ and draws 25 ma from the battery. A potentiometer is used to adjust the frequency of oscillation and to provide $1200 \mathrm{v}$ DC across the corona discharge tube which regulates the output voltage. The two 50 megohm resistors connected across the high-voltage output function as bleeder resistors to eliminate shock hazards during maintenance.

A charging circuit (figure 4) capable of supplying $400 \mathrm{ma}$ to the rechargeable battery is also mounted on the same circuit board as the high-voltage supply. A stepdown transformer and a half-wave rectifier circuit are used. Approximately 12 to 14 hours are required to charge a completely discharged battery. A connector mounted on the top panel is used to connect the charging circuit to AC power. A neon lamp mounted on the handle indicates when the battery is being charged. 


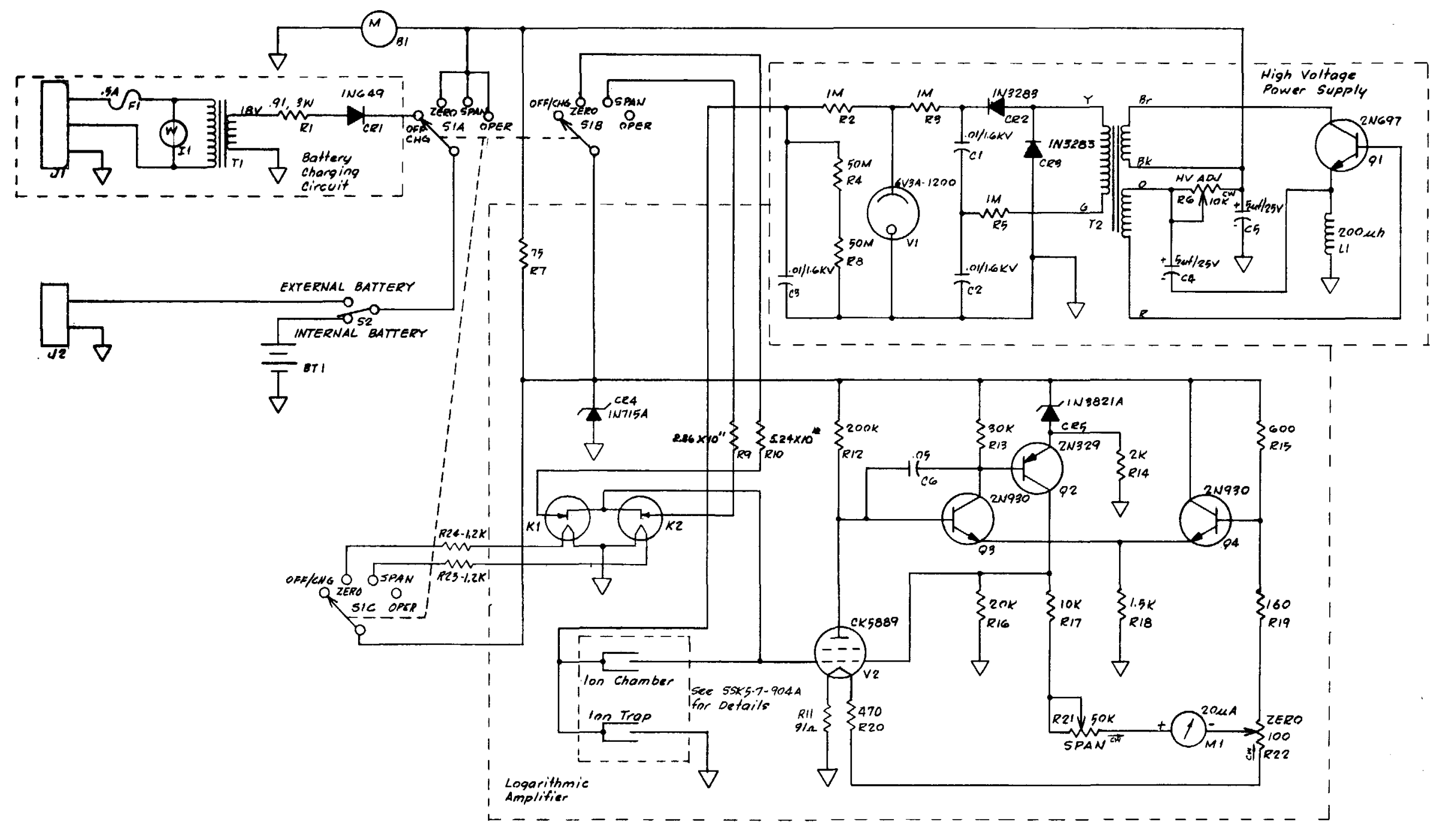

FIGURE 4. SCHEMATIC DIAGRAM OF TRITIUM MONITOR 


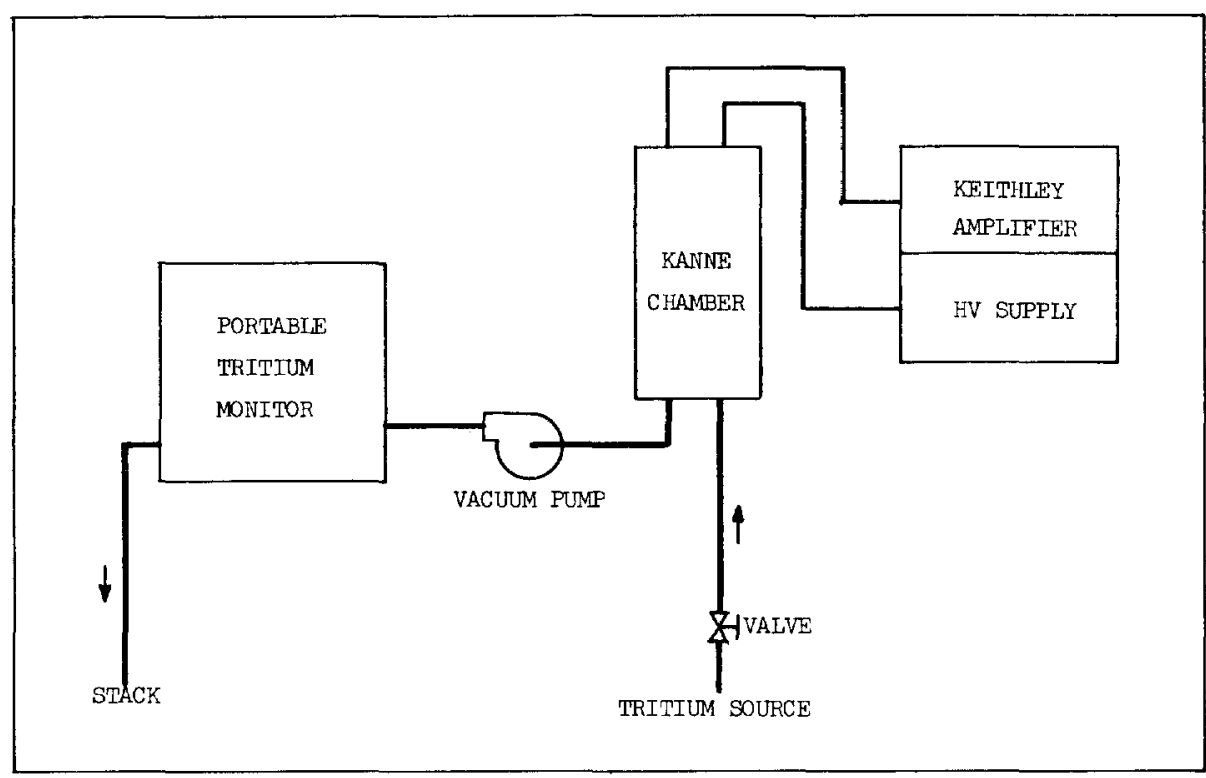

FIgURE 5. TESt ARRANGEMENT FOR CALIBRATING TRITIUM MONITOR

\section{INITIAL CALIBRATION}

The experimental arrangement shown in figure 5 was used to calibrate the monitor. The monitor was connected so that the air sample would also flow through an 18-liter Kanne chamber. Air-tritium mixtures were introduced into the series arrangement and allowed to come to a uniform concentration. The tritium concentration in the air was determined by measuring the current output from the Kanne chamber with a Keithley electrometer and using the conversion factor (1.46 $\times 10^{-8}$ $\mathrm{amp} / \mu \mathrm{Ci} / \mathrm{cc}$ of air) for an 18-liter Kanne chamber.

The table on page 7 compares the meter readings of the portable tritium air monitor and of the Keithley electrometer amplifier when sampling the same air samples during two different test runs. Lower levels of tritium concentration were obtained by diluting the tritium-air mixture with clean air. 


\begin{tabular}{|c|c|c|c|}
\hline \multirow[b]{2}{*}{ Run } & & \multicolumn{2}{|c|}{$\begin{array}{l}\text { Meter Readings, } \mu \mathrm{Ci} / \mathrm{cc} \\
\left.\text { (multiply by } 10^{-4}\right)\end{array}$} \\
\hline & $\begin{array}{l}\text { Sample } \\
\text { Number }\end{array}$ & $\begin{array}{l}\text { Portable Tritium } \\
\text { Air Monitor } \\
\end{array}$ & $\begin{array}{l}\text { Keithley } \\
\text { Amplifier } \\
\end{array}$ \\
\hline First & $\begin{array}{l}1 \\
2 \\
3 \\
4\end{array}$ & $\begin{array}{l}3.1 \\
11 \\
83 \\
380\end{array}$ & $\begin{array}{l}2.8 \\
11 \\
82 \\
410\end{array}$ \\
\hline Second & $\begin{array}{l}1 \\
2 \\
3 \\
4\end{array}$ & $\begin{array}{l}1.6 \\
15 \\
39 \\
250\end{array}$ & $\begin{array}{l}1.8 \\
14 \\
42 \\
270\end{array}$ \\
\hline
\end{tabular}

\section{ROUTTIE CALIBRATION}

Since routine calibration using tritium-air mixtures is impractical, a gamma field is normally used. The following calculation was used to determine the gamma field equivalent of a given air-tritium mixture.

For air containing a tritium concentration of $1 \times 10^{-4} \mu \mathrm{Ci} / \mathrm{cc}$, the current flow due to ionization within the ion chamber is:

$$
\begin{gathered}
I=\frac{(2900 \mathrm{cc})\left(1 \times 10^{-4} \mu \mathrm{Ci} / \mathrm{cc}\right)\left(3.7 \times 10^{-4} \mathrm{a} / \mathrm{s}\right)(5690 \mathrm{eV})\left(1.6 \times 10^{-19} \mathrm{C}\right)}{35 \mathrm{eV}}= \\
2.79 \times 10^{-13} \mathrm{amp}
\end{gathered}
$$

where: $2900 \mathrm{cc}=$ volume of ionization chamber

$3.7 \times 10^{-4} \mathrm{~d} / \mathrm{s}=$ disintegrations per second for 1 microcurie $5690 \mathrm{eV}=$ average energy of tritium betas in electron volts $1.6 \times 10^{-19} \mathrm{C}=$ charge of an electron in coulombs

$35 \mathrm{eV}=$ energy in electron volts, given up by tritium betas forming an ion pair.

By a similar calculation, it can be shown that a field of $1 \mathrm{mR} / \mathrm{hr}$ of gamma radiation will give a chamber current of $2.68 \times 10^{-13} \mathrm{amp}$. Using these values it can be shown that a $1 \mathrm{mR} / \mathrm{hr}$ ganma field causes the same current to flow as a tritium concentration of $9.61 \times 10^{-5}$ $\mu \mathrm{Ci} / \mathrm{cc}$ of air. 


\section{References}

1. Eutsler, B. C., et al, Instruments for the Monitoring of Tritium in the Atmosphere. Los Alamos Scientific Laboratory, LA-1909, Apri1 1955.

2. Price, W. J., Nuclear Radiation Detection. McGraw-Hill, New York, 1964.

3. Sharpe, J., Nuclear Radiation Detectors. John Wiley and Sons, New York, 1964.

4. Rossi, B. B., Ionization Chambers and Counters. McGraw-Hill, New York, 1949.

5. Bishop, S. R., A Logarithmic Current-to-Voltage Amplifier with High Sensitivity, Stability, and Dynamic Range, Suitable for Field Application. Lawrence Radiation Laboratory, UCRL 12394-T, October 1965.

6. Wall, G. F., and M. P. Young, An Eight-Decade Logarithmic Amplifier for Nuclear Reactor Instrumentation. Naval Research Laboratory, NRL 5025, October 1957.

7. Engineering Staff, Texas Instruments Inc., Transistor Circuit Design. McGraw-Hill, New York, 1963. 